\title{
DESPLACAMENTO DE REVESTIMENTO CERÂMICO EM FACHADAS - ESTUDO DE CASO
}

\author{
SEABRA, KÉDMA DA SILVA \\ Estudante \\ Universidade da Amazônia \\ Pará; Brasil \\ kedmaseabra30@gmail.com
}

\author{
DA SILVA, ALEX \\ Estudante \\ Universidade da Amazônia \\ Pará; Brasil \\ alex_q.silva@hotmail.com
}

\author{
SANTOS, ALBERTINO \\ Estudante \\ Universidade da Amazônia \\ Pará; Brasil \\ leonam_correia@hotmail.com
}

\section{RESUMO}

A fachada é como o cartão de visita do empreendimento, sendo um dos principais aspectos estéticos do mesmo, ela também corresponde à proteção e durabilidade da edificação. Porém, nenhum processo está livre de problemas, que não diagnosticados e tratados, ocasionam patologias com prejuízos significativos. Diante disto, este trabalho teve como objetivo apresentar, como estudo de caso, o processo de recuperação de uma fachada com pertinentes problemas patológicos de desplacamento cerâmico. A área de estudo trata-se de um edifício residencial de quarenta anos, situado na cidade Belém-PA, bairro Batista Campos, a edificação possui 21 pavimentos, contando com pavimento garagem e cobertura. A investigação dos possíveis motivos para o desplacamento cerâmico da fachada foi feito através das recomendações da Norma NBR 5674/2012 e uso da Ficha de Identificação de Dados (FID). Sendo assim, observou-se que o equívoco estava no preparo da base para o assentamento da antiga pastilha cerâmica, pois foi identificado restos de tinta na base onde o revestimento cerâmico foi executado, proporcionando fragilidade na aderência e maior incidência de vazios, possibilitando a entrada de água reagindo com a argamassa levando ao desplacamento.

Palavras-chave: fachada, desplacamento cerâmico, FID.

\section{ABSTRACT}

The facade is like the business card of the development, being one of the main aesthetic aspects of it, it also corresponds to the protection and durability of the building. However, no process is free of problems, which undiagnosed cause pathologies with significant damage. Given this, this paper aimed to present, as a case study, the process of restoration of a facade with relevant pathological problems of ceramic peeling. The study area is a 40 (forty) year old residential building, located in the city Belém-PA, Batista Campos neighborhood, the building has 21 floors, with garage floor and roof. The investigation of the possible reasons for the ceramic peeling of the façade was made through the recommendations of the NBR 5674/2012 Standard and use of the Data Identification Sheets (FID). Thus, it was observed that the misconception was in the preparation of the base for the laying of the old ceramic tablet, because it was identified paint remains in the base where the ceramic coating was performed, providing fragility in adhesion and higher incidence of voids, allowing the entry of water reacting with the mortar leading to peeling.

Keywords: facade, abstract, ceramic casting, FID.

\section{INTRODUÇÃO}

No Brasil, um dos sistemas de revestimento de fachadas mais utilizado é o cerâmico por ter diversas vantagens. A fachada é como o cartão de visita do empreendimento, por isso, se faz necessário ter conhecimento que esse sistema é mais complexo do que aparenta, pois existem diversos fatores que condicionam de forma direta o sucesso desse procedimento. Segundo Oliveira (2013), a utilização dos revestimentos cerâmicos em fachadas, é necessário 
devido à resistência a ambientes corrosivos, por proporcionar um baixo custo de manutenção, por não ocorrer um desgaste acentuado ao decorrer do tempo e facilidade de limpeza.

Sendo um dos principais aspectos estéticos de um empreendimento, a fachada corresponde também à proteção e durabilidade da edificação. Alguns materiais, como a cerâmica, são comumente utilizados para revestimentos de fachadas e propiciam diversos benefícios, como isolamento acústico e térmico, e a estanqueidade necessária para um razoável conforto nas edificações.

Porém, nenhum processo está livre de problemas, que se não identificados e tratados de forma correta levam a patologias que geram, muitas vezes, prejuízos significativos a um empreendimento. As razões que causam essas patologias estão ligadas a diversos motivos, tais como, preparo inadequado da base, limpeza mal executada e o preparo inadequado de argamassa colante, além da forma indevida de assentamento das placas cerâmicas.

A proposta de avaliar as patologias no revestimento cerâmico de fachada, com enfoque ao desplacamento cerâmico, é justificada por meio da observação de constantes casos na região. Este trabalho tem o intuito de contribuir para a redução de possíveis casos, enfatizando a gestão de manutenção (programa de manutenção), devido aos recentes desplacamento de fachadas gerarem para a sociedade efeitos desastrosos, tanto físicos, quanto materiais.

Por tanto, o objetivo deste trabalho, é enfatizar e diagnosticar uma das patologias mais frequentes no sistema de revestimento de fachadas, o desplacamento de pastilhas cerâmicas; ressaltar a importância de se possuir o conhecimento sobre as diversas patologias que esse sistema está sujeito e identificar possíveis anomalias que acarretaram o desplacamento do revestimento cerâmico por meio da ficha de identificação de dados.

Nas ocorrências deste caráter é necessário que suas causas sejam avaliadas tecnicamente e as soluções propostas estejam de acordo com os parâmetros estabelecidos por normas técnicas, para com isso prolongar a durabilidade e vida útil das fachadas e assim reduzir gastos com intervenção de reparo, por meio de técnicas preventivas.

\section{REFERENCIAL TEÓRICO}

\subsection{A Ficha de Identificação de Dados (FID's)}

A Ficha de Identificação de Dados (FID’s) a primeira etapa de avaliação da edificação, busca-se o maior número de informações para elaborar o diagnóstico do problema. Nela estão informações obtidas na primeira vistoria, in loco. Segundo I.C. Carvalho (2014), apud Falorca e Mendes Silva (2009), "Esta FID funciona como um método sistemático e impessoal de inspeção visual, considerada como a caracterização do estado da edificação em que, para cada fachada, deve haver precisão de dados coletados." Ou seja, é uma espécie de coleta de dados, onde é realizada a quantificação e qualificação das patologias analisadas visualmente. No entanto, é apenas uma amostragem e uma reunião dos danos apresentados no imóvel, e não a causa ou motivo da patologia.

A inspeção visual acontece durante a vistoria pelo ambiente, onde é anotado o maior número de dados possíveis, investigando, também através de questionários e entrevista os usuários e proprietários. Para isso é necessário possuir um preparo técnico para avaliar aspectos físicos do ambiente e do entorno da edificação.

\subsection{Diagnóstico dos Dados}

Após a FID’s já se tem uma ideia da possível causa da anomalia. A etapa seguinte passa a serem as investigações mais precisas com o objetivo de elaborar um parecer coerente com a realidade, ou seja, o diagnóstico dos danos. Essas duas fases e a intervenção de reparo, constitui o programa de manutenção.

Segundo DA SILVA (2014) a fase de diagnóstico consiste em estabelecer critérios, a partir das informações anteriores, que permitam estabelecer hipóteses para formular os mecanismos específicos responsáveis pela origem e desenvolvimento das anomalias que ocorrem nas fachadas inspecionadas. Ou seja, é um pré-requisito baseado nas informações já obtidas na primeira fase do programa de manutenção, sendo assim, é possível supor alguns prognósticos das falhas, para com isso processar a intervenção de reparo. 
Perez (1988) enfatiza que o sucesso dos trabalhos de manutenção numa edificação está atrelado ao diagnóstico de cada falha encontrada, desde deterioração natural até problemas decorrentes ao mau uso. Sendo assim, frisa-se a importância de um adequado diagnóstico do estado de conservação dos elementos de fachada, para com isso fomentar a durabilidade desses componentes.

\section{METODOLOGIA}

A área de estudo trata-se de um edifício residencial situado na cidade de Belém, bairro Batista Campos, a edificação possui vinte e um pavimentos, contando com pavimento garagem e cobertura. Além disso, a idade do prédio é quarenta e dois anos e em suas fachadas já foram realizadas três intervenções, uma a vinte e dois anos atrás em 1998 (substituição da pintura por pastilhas cerâmicas), outra há sete anos em 2011 (reparo no revestimento cerâmico desplacado) e uma com início em 2018 (subistutuição das pastilhas cerâmicas por placas de ACM) a qual compõe o estudo de caso analisado.

Fazendo um estudo comparativo de alguns métodos de gestão de manutenção de fachadas, criou-se um modelo de Ficha de Identificação de Dados, essa ficha foi utilizada in loco na visita técnica para auxiliar na vistoria, e registrar as patologias presentes nas fachadas do edifício residencial estudado.

O levatamento dos dados para o diagnóstico da patologia na fachada foi realizado no dia dezoito de outubro de 2018, o principal material utilizado foi a FID, no decorrer da visita técnica no canteiro a FID foi preenchida conforme os dados coletados, como ilustra a imagem (1). Vale ressaltar, que a vistoria foi realizada com a intervenção de reparo já iniciada, impedindo de se obter algumas informações como o mapeamento dos dados. O quarto item da ficha de identificação dos dados é destinado aos registros fotográficos, o qual possui um papel fundamental no diagnóstico da patologia.

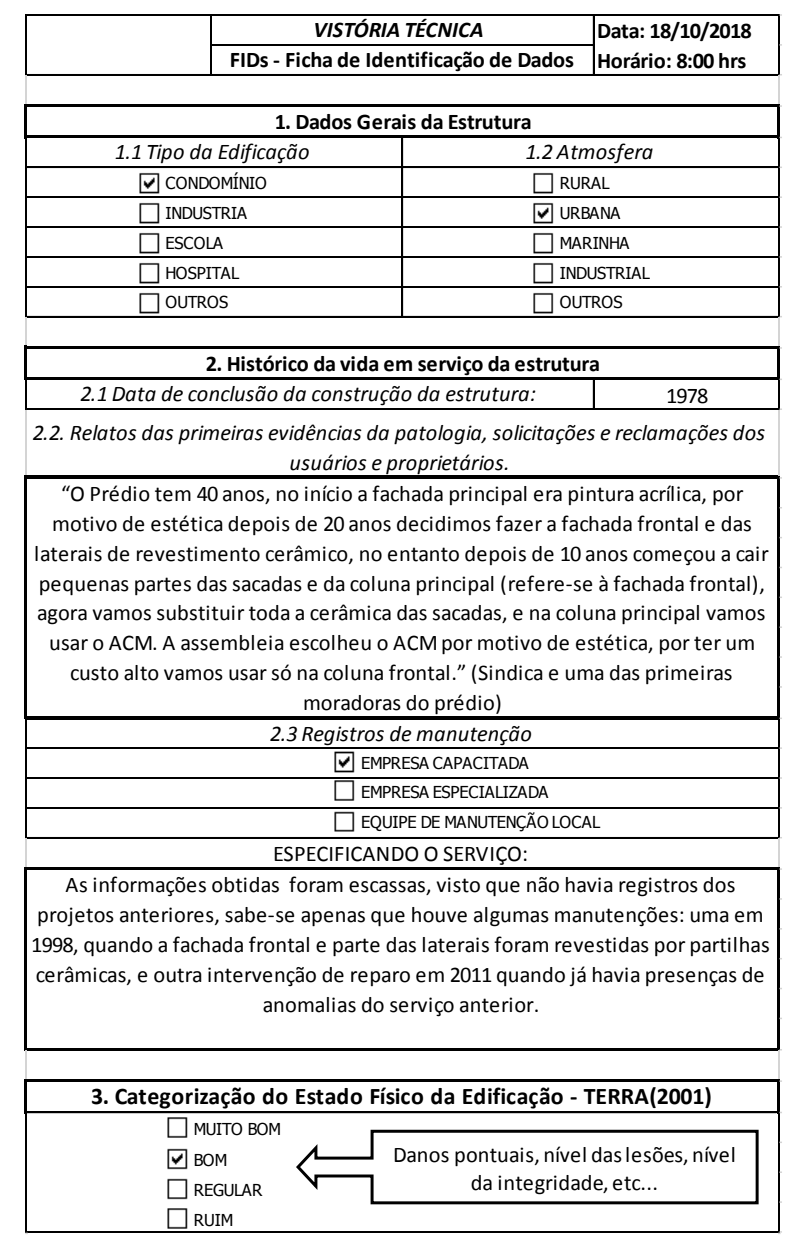

Figura 1: FID preenchida in loco 


\section{RESULTADOS E DISCUSSÕES}

Segundo a Norma 15571-2013, a vida útil de projeto (VUP) de vedação vertical externa é quarenta anos, ou seja, os projetos devem ser elaborados para que os sistemas de revestimento de fachada tenham uma durabilidade de potencial compatível com a VUP. Sabe-se que no caso do edifício residencial estudado, o sistema de revestimento de fachada - composta por pastilhas cerâmicas - apresentou as primeiras incidências de deslocamento e desplacamento cerâmico, logo após dez anos da conclusão. Sendo assim, a VUP nesse caso atingiu apenas $25 \%$ do mínimo estipulado pela Norma técnica de desempenho.

Durante a vistoria, verificou-se que houve falha de mão de obra no assentamento das pastilhas cerâmicas, sobre o antigo sistema convencional de pintura, pois como evidenciado nas imagens (2, 3 e 4), a aplicação do revestimento foi executado sem preparo adequado da base, visto que o revestimento estava com danos, patologias e fragilizado, criando assim, a necessidade de ser retirado antes da aplicação.

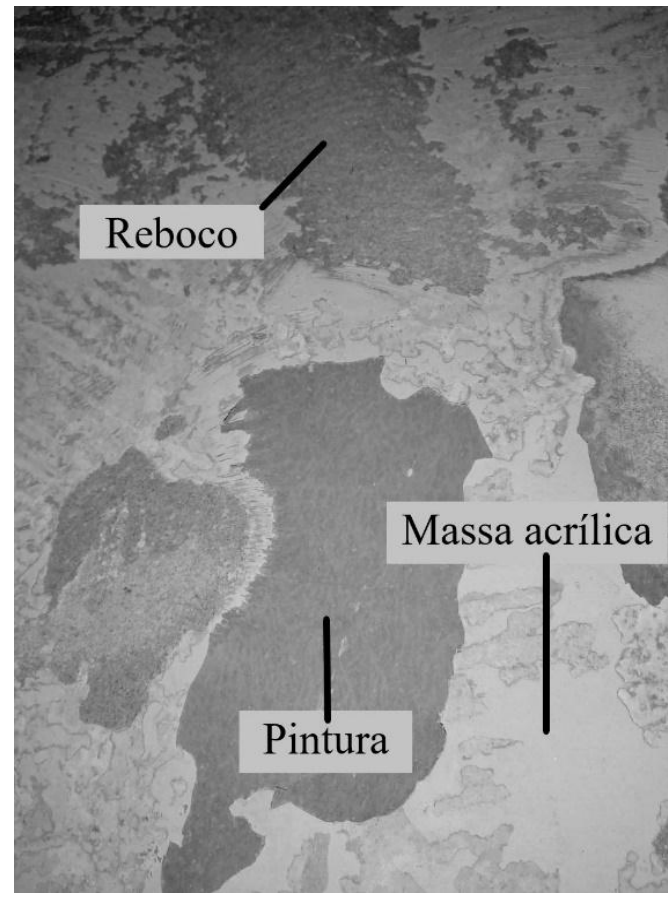

Figura 2: Substrato parcialmente lixado

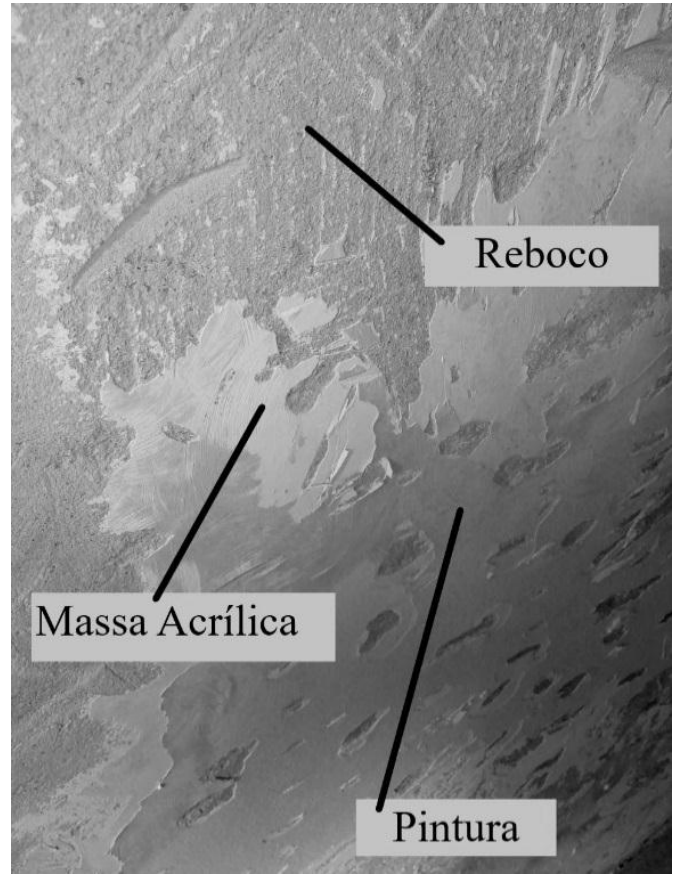

Figura 3: Sistema com anomalia, após remoção da cerâmica

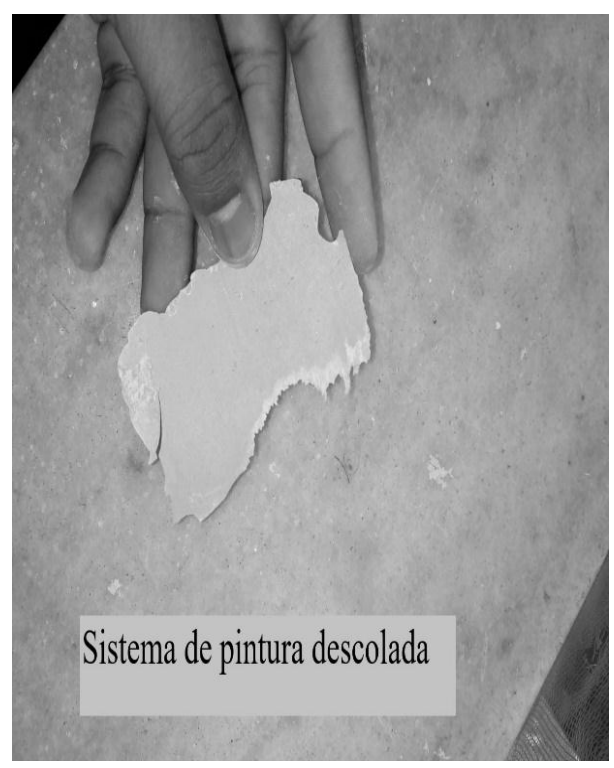

Figura 4: Sistema de pintura descamada. 
Além disso, de acordo com o responsável técnico pela obra, não haviam juntas de movimentação e dilatação, tanto vertical quanto horizontal, portanto, permitindo, sem o devido preparo de movimentação, os diversos tipos de atividades que a fachada está sujeita, que podem ser tanto estruturais, quanto expansão hidráulica, causadas pelas vibrações do edifício (vento, trânsito ou carga dinâmica), ou pela retração do revestimento de argamassa ou por variação térmica.

Ao se averiguar os possíveis motivos para o desplacamento por meio do diagnostico de dados e da FID, foi notório que o erro estava na execução e preparo da base para o assentamento, pois foi identificado restos de tinta na base, conforme as imagem (5 e 6), onde o revestimento foi aplicado, isso proporcionou fragilidade na aderência e maior incidência de vazios. Com isso, possibilitando a entrada de água reagindo com a argamassa levando ao desplacamento, de acordo com as figura (7 e 8).

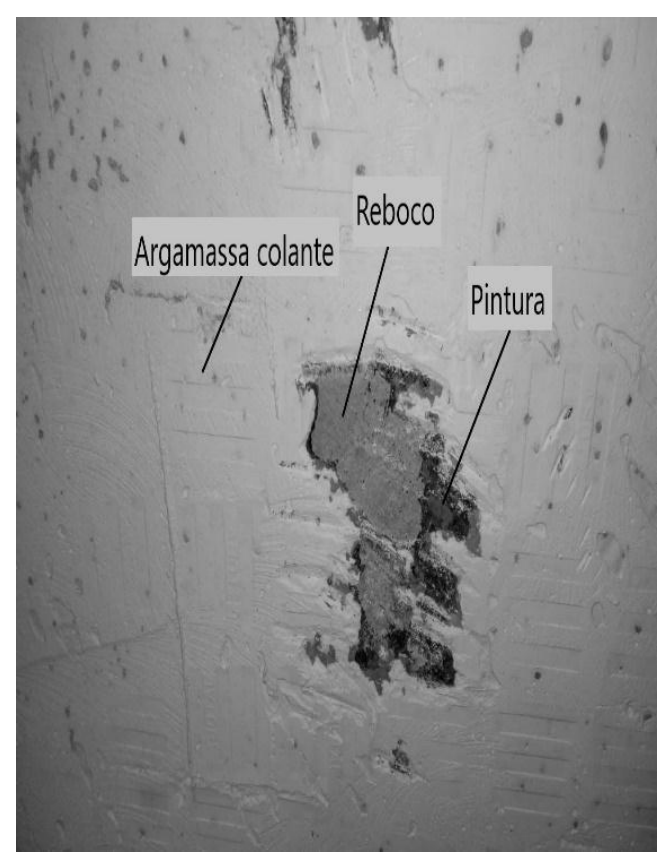

Figura 5: Sistema com anomalia

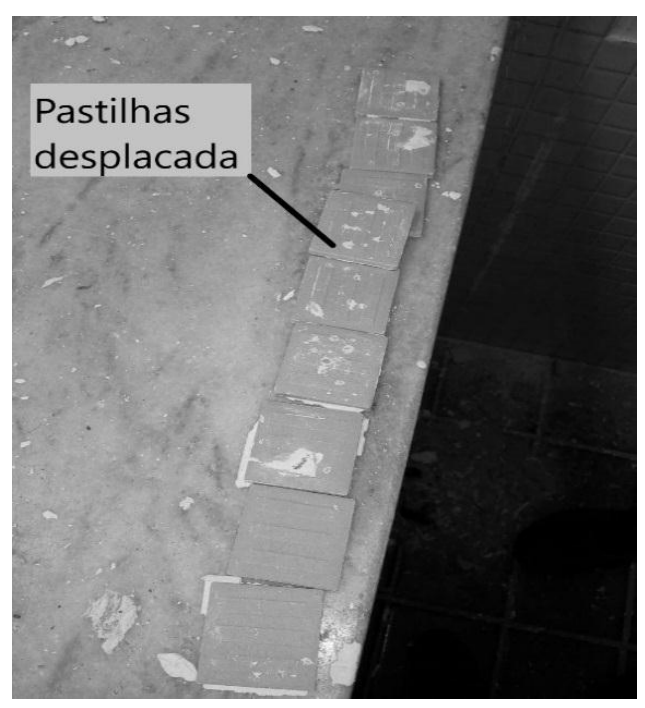

Figura 7: Pastilha cerâmica

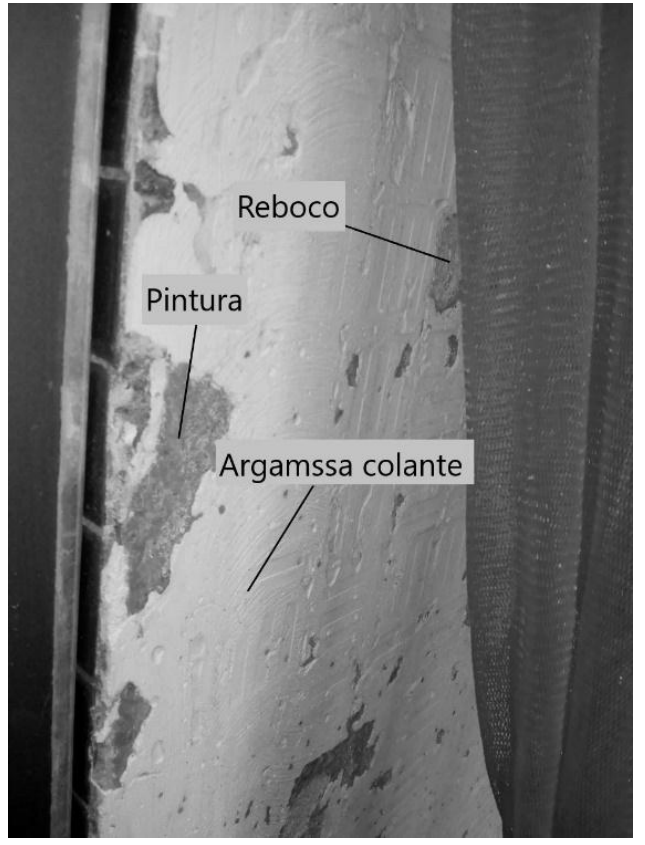

Figura 6: Sistema com anomalia

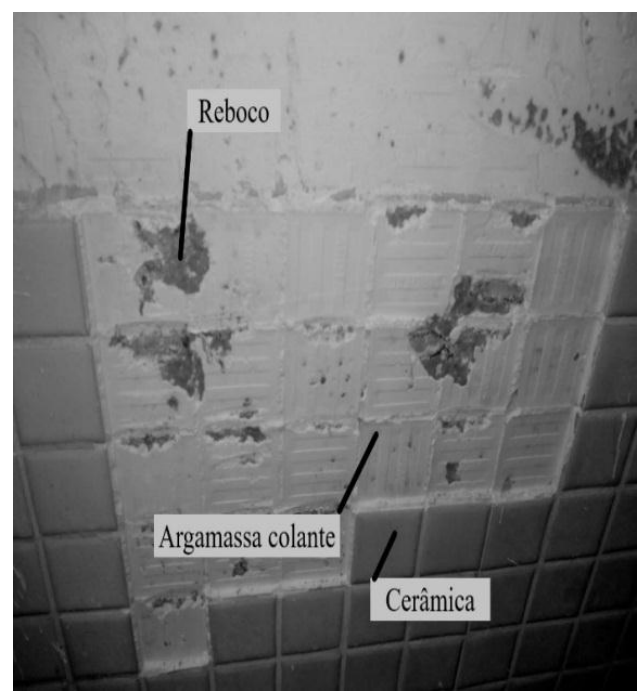

Figura 8: Desplacamento das pastilhas 
Com isso, frisa-se que a falta de juntas de dilatação somada ao assentamento das pastilhas cerâmicas diretamente no sistema de pintura, sem o preparo da base, proporcionou um acelerado agravante do desplacamento da pastilha. Além disso, é evidente que não houve a execução de um projeto para reforma da fachada, levando aos danos atuais e a necessidade de mais uma reforma.

\section{CONCLUSÃO}

Com isso, frisa-se que a falta de juntas de dilatação somada ao assentamento das pastilhas cerâmicas diretamente no sistema de pintura, sem o preparo da base, proporcionou um acelerado agravante no desplacamento da pastilha. Além disso, é evidente que não houve a execução de um projeto para reforma da fachada, levando aos danos apresentados e a necessidade de mais uma reforma.

Portanto, o sistema de revestimento de fachadas com pastilhas cerâmicas, sendo um dos métodos que mais apresenta vantagens, ainda assim não pode ser aplicado sem um estudo específico, pois a utilização incorreta ou em local inadequado acarretará em diversas patologias, entre elas o desplacamento. O qual ocorreu no edifício residencial estudado, no bairro Batista Campos, Belém, PA.

\section{AGRADECIMENTOS}

À Deus pelo dom da vida.

\section{REFERÊNCIAS}

Associação Brasileira de Normas Técnicas. (2013) "Edificações Habitacionais-Desempenho", Parte 1: Requisitos gerais, NBR 15575-1 (Rio de janeiro, Brasil)

Associação Brasileira de Normas Técnicas. (2012) "Manutenção de edificações- requisitos para o sistema de gestão de manutenção", NBR 5674 (Rio de janeiro, Brasil)

TERRA, Ricardo Curi. Levantamento de Manifestações Patológicas de Fachadas das edificações da Cidade de Pelotas. 2001.133p. Dissertação (Mestrado) - Programa de Pós-graduação em Engenharia Civil - Universidade Federal do Rio Grande do Sul, Porto Alegre.

BARRIENTOS, Maria Izabel; QUALHARINI, Eduardo. Retrofit de construções: metodologia de avaliação. In X Encontro nacional de tecnologia do ambiente construído, São Paulo, 2014.

COSTA e SILVA, Angelo Justa. Método para gestão das atividades de manutenção de revestimentos de fachada. 2008. 239p. Tese (Doutorado) - Escola Politécnica, Universidade de São Paulo, São Paulo, 2008.

CARVALHO, Isabella Chaves, et all, Identificação de patologias em fachadas e metodologia de análise: Estudos de casos na universidade federal do Pará. Revista Eletrônica de Engenharia Civil. Vol. 9 - nº 2, p. 38-56, out. 2014.
CICHINELLI,
Gisele.
Patologias cerâmicas
2006.
Disponível
em:

<http://techne17.pini.com.br/engenhariacivil/116/artigo287385-1.aspx>. Acesso em: 3 out. 2018. 